\title{
Amor maldito, motor da poesia: a Provença e a modernidade
}

\author{
Francesca Manzari
}

\begin{abstract}
Resumo: É a composição das vidas dos trovadores que confere ao Grand Chant a dimensão romanesca e ficcional que permitiu a construção de figuras "malditas" como Jaufre Rudel, Bertrand de Born, Raimon Jordan... Do amor cantado pelo trobar nasce o seu oposto destruidor: a melancolia, decorrente da ausência da dama, espreita o trovador, acenando-lhe o risco de não mais compor. Tal reflexão vai conduzir autores como Ezra Pound, Haroldo e Augusto de Campos a reconhecer na Provence dos séculos XII a XIII o lugar original, o topos outopos da poesia.
\end{abstract}

Palavras-chave: poesia provençal; trovadores; mal de amor; Ezra Pound; Haroldo de Campos

Résumé: C'est la composition des vidas des troubadours qui confère au Grand Chant la dimension romanesque et fictionnelle qui a permis la construction d'un certain nombre de figures "maudites": Jaufre Rudel, Bertrand de Born, Raimon Jordan... L'amour chanté par le trobar engendre son opposé destructeur: la mélancolie due à l'éloignement de la dame guette le troubadour, qui risque de ne plus savoir composer. Cette réflexion pousse les modernistes américains, Ezra Pound, Haroldo et Augusto de Campos, entre autres, à reconnaître en la Provence des XIle et XIIle siècles le lieu originaire, le topos outopos de la poésie.

\footnotetext{
Abstract: It is the composition of the troubadours' lives that confers to the Grand Chant a Romanesque and fictional dimension that allowed the construction of "damned" figures such as Jaufre Rudel, Bertrand de Born, Guillem de Berguedan, Folquet de Marseille, Raimon Jordan... From the love sung by the trobar, its destructive opposite is born -- melancholy, resulting from the lady's absence, awaits the minstrel, waiving at him the risk of no longer composing. Such reflection will lead authors as Ezra Pound, Haroldo and Augusto de Campos, to recognize in the Provence of the 12th-13th centuries the original place, the topos outopos of poetry.
}

Keywords: Provençal poetry; troubadours; melancholy; Ezra Pound; Haroldo de Campos 
Noigandres é o título da famosa revista-antologia publicada por Décio Pignatari em conjunto com Haroldo e Augusto de Campos, a partir de 1952. Essa palavra-manifesto, associada ao movimento da poesia concreta brasileira, desembarca no Brasil, vinda de muito longe, no tempo e no espaço: uma canso de Arnaut Daniel, trovador occitano do século XII, através dos Cantos de Ezra Pound.

O Canto xx de Pound começa com a citação dos célebres versos de Bernat de Ventadorn, trovador do século xII: "Si no'us vei, Domna don plus mi cal, Negus vezer mon bel pensar no val". ${ }^{1}$ Nenhuma visão, nenhum ver, vale a beleza do pensamento do trovador. Estamos rodeados de amendoeiras em flor, no mês de março. Pound menciona uma viagem a Freiburg im Breisgau para indagar The old Lévitron sobre o manuscrito settant'uno R. superiore da Biblioteca Ambrosiana de Milão. A pergunta refere-se a um verso de Arnaut Daniel, que contém uma palavra incompreensível: Noigandres.

Eis a passagem:

And I went to old Lévy, and it was by then 6.30 in the evening, and he trailed half way across Freiburg before dinner, to see the two strips of copy,

Arnaut's, settant'uno R. superiore (Ambrosiana)

Not that I could sing him the music.

And he said: Now is there anything I can tell you?"

And he said: I dunno, sir, or

"Yes, Doctor, what do they mean by noigandres?"

And he said: Noigandres! NoIgandres!

"You know for seex mon's of my life

"Effery night when I go to bett, I say to myself:

"Noigandres, eh, noigandres,

"Now what the DEFFIL can that mean!"2

A copla na qual aparece a palavra Noigandres é a primeira da Canso Er vei vermeills vertz blaus blancs gruocs e, segundo a tradução proposta por Peter Makin, significaria:

1. Na tradução de A. S. Kline: "Lady I can't leave, if I see you not,/ No sight is worth the beauty of my thought" (http://colecizj.easyvserver.com/povencar.htm).

2. Pound, Ezra. Canto XX. In: The Cantos. New York: A New Directions Book, 1996 [1970], p. 89. 
Now I see scarlet, green, blue, white and yellow the orchards, plains, hedges, hillocks and dales, and the song of the birds sounds and resounds with sweet harmony in the morning and late. This puts in my heart to colour my song with a flower, such that its fruit be love, its seed joy, and its scent protection from distress. ${ }^{3}$

As cores da primavera e os pássaros cantando trazem alegria ao coração do trovador. Arnaut Daniel emprega aqui uma metáfora para a poesia: uma flor cujo fruto será amor, a semente le joy e o perfume, um escudo contra a angústia. Então tudo começa assim, a grande aventura de Noigandres está vinculada ao valor simbólico dessa palavra que carrega em si a própria essência da poesia.

Trata-se de um hapax legomenon, enoi gandres, "que protege do tédio": The old Levy, citado por Pound é Emil Levy, que havia proposto uma interpretação para a palavra em 1904, ${ }^{4}$ relacionando-a a gandir, verbo ao qual Pound dizia nem mesmo haver pensado. Noigandres é o elixir da poesia, a via de sobrevivência, de sua resistência a uma maldição: a tristeza.

É a composição das vidas dos trovadores que confere ao Grand Chant a dimensão romântica e ficcional que permitiu a construção, ao longo dos séculos, de várias figuras "amaldiçoadas": Jaufre Rudel, Bertran de Born, Guilhem de Berguedan, Folquet Marselha, Raimon Jordan... O amor cantado pelo trobar cria seu oposto destrutivo: a melancolia, fruto do afastamento da senhora, paira sobre o trovador que corre o risco de não mais ser capaz de compor. Assim a maldição adquire, na Provença, um caráter sagrado: compõe-se para evitar sofrer a maldição do mal de amor que enfraquece os poderes criativos do poeta. A melancolia passa então a ser maldição e bênção da poesia, seu motor, sua força vital, assim como sua dimensão metacrítica, sua origem e seu limite.

Em La Fleur inverse, Jacques Roubaud propõe uma leitura sobre o nascimento do trobar e que segue exatamente esta linha: um nascimento que de imediato anuncia a sua cor teórica e metacrítica: "No campo das rimas, na teoria do amors percebeu-se pela

3. MAkin, Peter. Provence \& Pound. Berkeley and Los Angeles: University of California Press, 1978, p. 178 .

4. Na publicação Suplement-Wörterbuch. 
primeira vez a conexão, que está longe de deixar de influenciar os poetas, da melancolia com a memória, a impossibilidade de dizer e a impossibilidade de não dizer que marcam a tensão da poesia entre sua forma e o nada".

Uma das primeiras cansos de Guilhem Ix d'Aquitânia, primeiro trovador, explica a situação paradoxal do trobar. Ela diz "Farai un vers de dreit nien" [Farei um verso do mais puro nada]. ${ }^{6}$ Esta canso cujo mais famoso trecho é o joc parti, tenso entre Aimeric de Peguilhan e Albertet Sisteron, "Amics Albert tenzos soven" [Amigo Albert desafiemo-nos mais] ", insere desde o princípio o trobar no jogo aporético: ele não tem objetivo, o que ele canta é o nada, pertence tão somente àquele louco, que, dentre os loucos de amor, foi tocado por uma fada. Essa fada desencadeia amor, criando a sua origem e indicando seu limite.

Limite, fim, que, na arte de compor, coincide com a particularidade própria de cada canso, de dizer, de conter, de forma sempre renovada, completa e mensurável, o incomensurável do amor. Paira sempre sobre o trovador o sentimento de amar demais, do amor louco que leva à perda de medida e à impossibilidade de compor, à incapacidade de honrar o compromisso do Grand Chant, de seus códigos.

A famosa tenso do início do século xIII descreve como o trobar brinca com sua própria maldição e seu limite: escapar do arrebatamento do que se deve, de toda maneira, cantar: o amor. E assim, cantar o lado fugidio do objeto do canto. Isto também permite responder à pergunta de saber por que a Provence dos séculos XII e XIII se torna relevante para a modernidade e isto especialmente a partir dos Cantos de Ezra Pound.

A maldição que paira sobre o trovador é exorcizada pelo tema sempre presente, no repertório dos trovadores, da coincidência entre o amor e o nada.

A Canso de Guillaume Ix d'Aquitaine, "Faray un vers de dreit nien" [Farei um verso do mais puro nada], e a tenso ${ }^{8}$ entre Aimeric de Peguilhan e Albertet de Sisteron são parte da tradição dos textos que contribuem a definir a especificidade de trobar em torno de um jogo meramente formal cujo conteúdo permanece indecifrável.

O confronto poético entre Aimeric de Peguilhan e Albertet Sisteron deve ter ocorrido provavelmente por volta de 1230. Trata-se de uma tenso, e mais especifica-

5. Roubaud, Jacques. La Fleur inverse, Paris: Les Belles Lettres, 2009 [1994], p. 345.

6. Id., Les Troubadours, anthologie bilingue. Paris: Sehers, 1971, p. 70-73.

7. Id., pp. 264-267.

8. A tenso é um duelo entre dois trovadores, muitas vezes em torno da definição do amor. 
mente um partimen, no qual o primeiro trovador a cantar, neste caso Aimeric, lança um desafio, a ser contestado por seu interlocutor. O partimen é um joc partit, um jogo compartilhado "como aquele outro jogo que é objeto por excelência, afirma Roubaud, o amor, que é ao mesmo tempo jogo e alegria". ${ }^{9}$ Este partimen é o mais original que nos chegou, pelo fato de que o desafio de Aimeric parece, pelo menos de forma aparente, não entrar no contexto específico dos debates em torno da definição de amor. É, por outro lado, o próprio Aimeric que faz tal afirmação: "mas ieu faz zo q'anc om non fes. tenzon d'aizo qi res non es", "mas eu faço o que homem algum jamais fez, faço repentes sobre o que não existe". ${ }^{10}$

O objeto do canto torna-se então fugidio, um movimento no espaço, uma forma que torna intangível seu conteúdo. O objeto do amor é fugidio, mas sua busca é infinitamente codificada. A forma de olhar supera o ambicionado, diria Walter Benjamin. Cabe a este caminho N (negativo) do Trobar, caminho metacrítico, sinalizar o que está por vir no Grand Chant. A questão da negatividade do amor também é a de uma poesia que transparece quando o objeto lírico percebe o seu próprio caminho para a perdição. Em uma canso conhecida pelo título "Doutz brais et critz" [Doces ruídos e gritos], Arnaut Daniel anuncia a espera por joy, que o tocaria, depois de um encontro com a Senhora, marcado em um quarto do palácio onde o casal estará "deitado". A figura da Senhora deitada à luz da lâmpada, que é sempre a luz do amor no Trobar, é uma das mais originais convenções trovadorescas. Arnaut aspira fazer um com ela. Mas duas coblas adiante, Arnaut compreende que está prestes a atingir o limite, "doncs ben sui fols que quier tan qe-m rependi que jes Amors non a poder qe-m cobra ni savis es nuls om qui joi acampa" [sou louco por querer tanto que me arrependo o amor não tem o poder de me proteger o homem sábio não afugenta a sua alegria]. ${ }^{11} \mathrm{O}$ escudo contra a

9. Roubaud, Jacques. La Fleur inverse, op. cit., p. 26. Roubaud aprofunda a definição de partimen, analisando sua forma em detalhe. No início de cada introdução, no início de cada cobla, ao retomar a palavra, o trovador deve, segundo as regras do jogo, refutar o que acaba de ser dito. Essa introdução é também "um tempo de repouso relativo, tanto para o trovador como para o ouvinte". Nesse meio tempo, o trovador prepara sua resposta feita de rimas, sílabas e "razões" de forma que tudo pareça improvisado. "E, ao mesmo tempo em que a cobla começa sem surpresa e se encaminha para um final novo e mais contundente, o interesse imediato, que uma arte oral não pode nunca negligenciar, é mantido vivo pelas doces palavras da alusão". Id., pp. 30-31.

10. Id., p. 23.

11. RoubaUd, Jacques. Les Troubadours, anthologie bilingue, op. cit., pp. 234-235. Nós destacamos. 
angústia, noigandres, portanto, não é amor, mas a forma, uma forma suficientemente refinada para poder sugerir a fuga do ser amado. O joy está sempre em estado de fuga.

A pergunta feita pelo caminho $\mathrm{N}$ do Trobar não se refere aparentemente à definição de amor, mas ao que não existe, ao nada, e deste "nada" a tenso entre Aimeric de Peguilham e Albertet de Sisteron leva seu nome, tenso du non re, repente do nada. Na realidade, o que deveria ser o desafio nesse partimen não o é, uma vez que não há possibilidade antinômica a uma tenso, que se assume como o nada: não há, estritamente falando, uma tese, uma posição a escolher dentro desse jogo compartilhado. Roubaud chama a atenção para a particularidade deste partimen: "Aimeric não diz o que é exatamente a contradição à qual ele pensa para dizer o que é o nada, nem qual é o desafio que ele lança por meio de 'nien', nem mesmo em que 'nien' seria suscetível de possuir duas definições entre as quais Albertet teria que escolher". ${ }^{12}$ Se essa razo tivesse sido semelhante às que são normalmente lançadas pelos trovadores, Aimeric não teria destacado a dificuldade do desafio: "qa razon pro-m respondrias . mas al nien vueil respondatz sobre qualquer assunto dar-me-ias facilmente uma resposta, mas é ao nada quero tua réplica”.13 Roubaud sugere que este repente não deve ser tomado como tal, mas como um paradoxo tão difícil de desvendar que o próprio partimen corre o risco de "não ser": "ao mesmo tempo em que o desafio sobre o nada, que ele faz sem rodeios, e visto que todo partimen é um desafio, Penguilhan o desafia sobre o nada contido em seu repente, o desafio da própria viabilidade do partimen, justamente no momento em que ele se inicia". ${ }^{14}$ Assim o questionamento recai também sobre a forma e o partimen acaba por fazer um desafio reflexivo, tal como o de um partimen que se reflete no espelho, perguntando-se se de fato é um partimen: "o que significa que, como o partimen é o poema do nada, e que o nada aqui é

12. Ibid., p. 27. Para dar um exemplo do que um partimen habitual deveria ser, Roubaud dá o exemplo do partimen de Gaucelm Faidit com o Conde da Bretanha. Trata-se de escolher entre duas alegrias: "Jauseume quel vos est semblan . que l'om or doi mieus mantenir . cant tant a conquis fins amant. q'il en est venuz au jezir. e sa dame l'onore tant . qu'elle met sor lui le choizir. d'un dous fere et penre en beizant. al comensar o al partir. sens plus dites vostre talant. le quel penriez vos avant. al conje o a l'avenir" [Gaucelm dê-me sua opinião, que escolha deve ser defendida tendo conquistado um fino amante este veio deitar-se e sua senhora o honra tanto que lhe dá a opção de escolher um doce fazer e tomar beijando ao chegar ou ao partir diga-me qual é seu desejo qual escolher ao sair ou ao chegar?]. Id., p. 26.

13. ROUBAUD, Jacques. La Fleur inverse, op. cit., p. 23.

14. Id., pp. $27-28$. 
antonímia, a réplica também deve sê-lo: este partimen é isto e aquilo, seu contrário". ${ }^{15} \mathrm{Em}$ outras palavras, este partimen se apresenta como o partimen por excelência, aquele que desafia sua própria existência, o seu status e sua função. Ao se apresentar assim, como a tenso du non re, ele deve mostrar como o nada pode ser um partimen, para descobrir como qualquer tenso tem em realidade o nada como objeto, um nada que é tudo e nada, tudo e vazio, algo e seu contrário. De qualquer forma, o exercício faz parte da tradição do trobar clus e o desafio lançado por Aimeric Albertet está entre os mais difíceis. Roubaud resume o jogo compartilhado sobre o nada da seguinte forma:

Passa então a ser responsabilidade de Albertet, em sua primeira cobla (estrofe) de réplica, não apenas responder, mas fazê-lo de forma que tudo o que é dito faça parte de um partimen, e de um nada. Na sequência Aimeric lança a sua tréplica, e assim por diante até o fim do duelo de cantos. A tarefa é difícil. Aimeric, que é o contrário de Albertet, neste duelo, é um oponente temível. ${ }^{16}$

Entretanto, voltando às palavras usadas por Aimeric para descrever seu partimen, Roubaud mostra que a escolha léxica é muito próxima à de um célebre diálogo, referência filosófica muito difundida na época, entre Alcuin e seu principesco discípulo Pepin. Esta é a conclusão da Pippini Regalis et Nobilissimi Juvenis Disputatio cum Albino Scholastico, um compêndio de charadas entre Alcuin e seu aluno Pepin, que ficou célebre na corte carolíngia. O diálogo procura definir objetos do mundo. Eis o seu incipit (introdução):

\footnotetext{
Pippinus. Quid est littera? - Albinus. Custos historiae.

P. Quid est verbum?- A. Proditor animi.

P. Quis generat verbum? - A. Lingua.

P. Quid est lingua?- A. Flagellum aeris.

P. O que é a letra? A. A guardiã da história.

P. O que é a palavra? A. A revelação do espírito.

P. Quem produz a palavra? A. A língua.

P. O que é a língua? $\mathrm{O}$ açoite do ar. ${ }^{17}$
}

15. Id., p. 28.
16. Id., p. 28.
17. Tradução proposta por Roubaud, in: La Fleur inverse, op. cit., p. 29.

136. MANZARI, Francesca. Amor maldito, motor da poesia 
E o texto segue assim até a conclusão sobre o nada:

Quid est quod est et non est? P. Nihil.

Quomodo potest esse et non esse [est]? P. Nomine est, et re non est.

O que é e não é? P. Nada

Como pode ser e não ser? P. Trata-se de uma palavra e não de algo. ${ }^{18}$

Se for verdade, escreve Roubaud, esta referência é significativa para a interpretação do partimen entre Aimeric e Albertet, é uma referência à indicação do sentido atribuído ao nada na tradição da teologia negativa. Revemos, então, ao ler um artigo de Alexander Leupin intitulado Deus, o Poeta e a Senhora,${ }^{19}$ no qual se recorda que "na teologia, o conceito do nada esbarra no ser por excelência, na substância imaterial de todas as substâncias, Deus, presente e eterno". Leupin refere-se a uma carta escrita por Frédégise, Abade de St. Martin de Tours, a Charles le Chauve e aos nobres de sua corte para responder à complexa pergunta de saber se "nihil é algo ou nada". A resposta dada é bem diferente da que Alcuin propõe a Pippinus uma vez que "segundo Frédégise, toda palavra define algo", portanto, "ocorre que nihil deve designar algo". O raciocínio parece remeter de forma óbvia ao texto do Gênesis, sobre a escuridão primordial, e ao comentário agostiniano sobre tal fato:

Não era um nada absoluto, mas algo disforme, desprovido de qualquer figura. Esta matéria, como denominá-la, como sugerir alguma ideia, mesmo às mentes menos privilegiadas, a não ser pelo uso de uma palavra do vocabulário corrente? Pode-se encontrar em todo o universo algo que se pareça mais com uma deformidade vaga do que a terra e o abismo? (Confessions xII, iii, 3-4).

Esta citação de Confessions mostra como a tradição teológica nega a existência do nada. Se o nada é assim levado a definir o status do trobar pela razo de Aimeric de Peguilhan, isto implica que tal escolha não é desprovida de um toque irônico em relação ao pensa-

18. Ibid.

19. Leupin, Alexander. "Dieu, le Poète et la Dame". In: Mélanges offerts à Roger Dragonetti. Paris: Champion, 1996, pp. 299-314. Disponível no site http://www.alexandreleupin.com/publications/ DieuPoeteDame.htm. 
mento cristão do qual o canto trovadoresco se liberta desde o seu surgimento. Jacques Roubaud lembra que o sentido da tenso du non re somente pode ser percebido em sua plenitude, graças à referência intertextual a uma canso de Guillaume Ix d'Aquitaine, Farei um verso do mais puro nada.

A prática da alusão é uma poderosa estratégia na arte do partimen, graças à qual os trovadores despertam de imediato o interesse de seu público. Assim, a tenson du non re não é em absoluto uma exceção a esta regra e se apresenta como um entrelaçamento denso de réplicas, ecos, alusões a outros poemas famosos da tradição à qual pertence. Para Roubaud, "a partir do primeiro verso de sua primeira réplica, Albertet busca com cuidado fazer ressurgir a figura do primeiro trovador, situado pelo trobar na origem, Guillaume Ix d'Aquitaine, [...] isso, através das palavras ' $d r e g$ nien', o 'puro nada"'. ${ }^{20}$

As figuras e os versos dos trovadores também aparecem numerosos, assim como nos anos dourados da Provença dos séculos XII e XIII, quando entrebescar recaía no conhecer o trobar em sua totalidade e poder aproveitar essa habilidade, nos cantos de Ezra Pound, que são, entre outras obras de referência e fundadoras, a dimensão sonhada pelo grupo Noigandres. Os séculos XII e XIII provençais e italianos adquirem na escrita dos Cantos um lugar privilegiado, não único evidentemente, uma vez que é compartilhado, entre outros, com a Grécia antiga. A referência à Provença, origem da poesia linguagem comum, é o antídoto contra a angústia que paira sobre a poesia moderna.

Nos Cantos, a Provença assume a mesma importância que a Grécia antiga, e, de forma quase unitária, ambas contribuem para configurar um topos outopos, como o chamaria Agamben, que seria a casa da poesia, a sua própria atemporalidade. Mas frente a esse paralelo, dois caminhos se definem na produção poética de Pound: caminhos contraditórios, um que veria os anos dourados da poesia, em um passado para sempre extinto, ao qual o poeta confere uma dimensão mítica, jogo possível graças aos conhecimentos adquiridos durante estudos de filologia, e depois, um caminho surpreendentemente progressista, o da tradução, ao abrigo de um slogan que marcará para sempre o século xx: "Make it New".

O que ocorre a nível teórico, a elaboração teórica dos caminhos da poesia moderna, ocorre por antecipação no campo do experimento em tradução com um

20. roubaud, Jacques. La Fleur inverse, op. cit., pp. 31-32. 
momento-chave, que é a tradução dos cansos de Arnaut Daniel. Parece-me haver duas ideias distintas que respaldam o trabalho realizado por Pound a partir dos trovadores: de um lado, um caminho que se dedica a teorizar sobre certa incapacidade do inglês de expressar coisas ditas pelo occitano do século XIII, o outro o da perfeição formal, conferida pelo idioma nativo da poesia comum ocidental, mas também por uma tradição poética que é o Outro da expressão poética inglesa.

Volto a um trecho do prefácio escrito por Ezra Pound para a tradução dos Sonetos e Baladas de Guido Cavalcanti e que também serviria para seu trabalho sobre Arnaut Daniel:

It is conceivable that poetry of a far-off time or place requires a translation not only of word and of spirit, but of "accompaniment", that is, that the modern audience must in some measure be made aware of the mental content of the older audience and of what these others drew from certain fashions of thought and speech. Six centuries of derivative convention and loose usage have obscured the exact significances of such phrases as:"The death of the heart", and "The departure of the soul".

A questão aqui é interpretar o que Pound entende por uma "tradução que não é apenas da palavra e de espírito, mas de acompanhamento". Para ele, traduzir e escrever andam de mãos dadas, como para Haroldo e Augusto de Campos, e a prática da tradução na produção desses poetas é acompanhada de uma utilização quase exacerbada do multilinguismo.

A prática/poética do multilinguismo é extremamente frutífera em Cantos, parece efetivamente ser o oposto da prática da tradução. No entanto, esta prática chega a Pound a partir da tradução, derivando da própria relação com a língua estrangeira.

21. Nossa tradução: "É concebível que a poesia de um tempo distante ou, de um local distante exija, não apenas uma tradução da palavra e do espírito, mas também de 'acompanhamento', pois o público moderno deve de alguma forma ter ciência sobre os conhecimentos do público antigo e de que este assumiu certos modos de pensamento e de discurso. Seis séculos de convenções pouco originais e usos vagos obscureceram o significado exato de frases como: 'a morte do coração' e 'a partida da alma", Ezra Pound, Introduction, Sonnets and Ballate of Guido Cavalcanti. Londres: Stephen Swift and Co., 1912, p. 2. Outras publicações: Pound, Ezra. Sonnets and Ballate of Guido Cavalcanti. Boston: Small, Maynard, 1912, também publicado em Ezra Pound's Cavalcanti Poems. New York: New Directions, 1966. 
Certa prática da escrita/composição dos Cantos faria com que a poesia se manifestasse em uma dimensão arqueológica e ao mesmo tempo de fuga para frente e isso passaria por uma relação com a língua e a poesia provençal. Portanto, haveria trovadores ressoando na escrita poundiana.

Essa posição poundiana decorre de uma mudança de atitude em relação à tradução, isto depois de ter traduzido Arnaut Daniel e Cavalcanti. Mas até que ponto o fato de ter tentado traduzir os trovadores e os poetas italianos do século XIII interfere na poesia de Pound? Não é uma pergunta banal, basta pensar em Haroldo de Campos, tradutor brasileiro de Pound, que teoriza, a partir do Make it New, a tradução multilíngue transluciferina.

O idioma provençal desperta o interesse do poeta por apresentar uma "parataxe de sons", "o idioma parece acolher de forma favorável as separações. Suas palavras ressoam, delimitando as sílabas claras e bem distintas que o francês moderno tornou indistintas ao omitir as consoantes finais. Lalba e l jorn clar torna evidente a gama de sons tanto que a alba e o dia claro os tornam desbotados".22 Renovar a poesia em língua inglesa significa, portanto, ao mesmo tempo, tornar novamente as palavras audíveis e destacadas, preferir o gosto de Arnaut Daniel pela separação ao de Tennyson pela fusão que as torna indistintas e une palavras e sílabas. A separação consonantal clara, típica do provençal, tem o mérito de chamar a atenção para a palavra e sua consistência autônoma.

Sobre a história de suas traduções de Arnaut Daniel, em Literary Essays, Pound diz a seus alunos:

As traduções são improvisadas. Não se vai esperar de mim que eu faça em dez anos o que os trovadores fizeram em dois séculos e meio, a compreensão profunda do sistema de ecos e de mescla de Arnaut. Não há maneira de substituir o original. Mas na atenuação da linguagem de meus versos, gostaria de salientar que os Provençais não eram pressionados pelo sentido literário moderno. ${ }^{23}$

Tudo se encontra, de fato, nessa afirmação. O que ele vê no sentido literário moderno? Ele prossegue: "Suas pressões eram a ária/melodia, o padrão rítmico, eles não eram coagidos pela necessidade de escrever com determinada qualidade literária, sem a qual

22. Kenner, Hugh. The Pound Era. Berkeley: University of California Press, 1973, p. 116. Nossa tradução. 23. Pound, Ezra. Literary Essays. Nova York: New Directions, 1968, p. 115. Nossa tradução. 
nenhum poema moderno está completo ou satisfaz. Eles não competiam com a prosa de Maupassant". ${ }^{24}$

Pound teoriza de início uma presença/ausência, na poesia moderna, de uma qualidade que teria pertencido apenas aos poetas italianos da Idade Média e que não tem equivalente desde então. $\mathrm{O}$ ato de traduzir viria, então, em sua concepção, preencher uma lacuna. Não seria, portanto, uma busca por uma linguagem equivalente, mas um processo criativo real: fruto do pensamento do poeta, que deve revelar o que permanece escondido, a maldição e sobrevivência da origem provençal da poesia.

Francesca Manzari é professora de Literatura comparada na Universidade de Aix-Marseille. Publicou o livro Écriture derridienne: entre langage des rêves et critique littéraire (Editions Peter Lang, 2009) e organizou, com Fridrun Rinner, a edição da coletânea de ensaios Traduire le même, l'Autre ou le soi (Presses de l'Université de Provence, 2011). Dirige, desde 2011, o mestrado "Tradução literária e interculturalidade" e trabalha atualmente com as leituras e reescrituras modernas e contemporâneas do Grand Chant, em Ezra Pound, James Joyce, Jacques Roubaud e outros escritores.

24. Ibid. 